\title{
Da voz à letra: itinerários da literatura afro-brasileira
}

\author{
ZILÁ BERND \\ Universidade Federal do Rio Grande do Sul (Porto Alegre, Brasil)
}

\begin{abstract}
RESUMO: O ARTIGO TEM POR OBJETIVO DISCUTIR OS CONCEITOS DE LITERATURA NEGRA E AFRO-BRASILEIRA, APRESENTANDO OS RUMOS DESSA LITERATURA INICIADA COM A EMERGÊNCIA DE UM EU ENUNCIADOR QUE SE QUER NEGRO NA POESIA, DESDE O SÉCULO XIX, COM LUÍS GAMA, ATÉ OS DIAS DE HOJE, EM QUE SE VERIFICAM DUAS TENDÊNCIAS DE CONSTRUÇÃO IDENTITÁRIA: O ENRAIZAMENTO (RAIZ ÚNICA) E O ENRAIZAMENTO RELACIONAL E DINÂMICO (RIZOMA), DESTACANDO-SE AINDA A SIGNIFICATIVA PRESENÇA DA POESIA NEGRA NO FEMININO.
\end{abstract}

ABSTRACT: THIS ARTICLE AIMS TO DISCUSS THE CONCEPTS OF BLACK LITERATURE AND AFRICAN BRAZILIAN LITERATURE, TRACING THE DEVELOPMENT OF THIS BODY OF WRITING FROM THE EMERGENCE OF AN I-ENUNCIATOR THAT WANTS TO BE BLACK IN POETRY FROM THE XIX ${ }_{\text {TH }}$ CENTURY, WITH LUÍS GAMA, TO THE PRESENT DAY. TWO TRENDS IN IDENTITY CONSTRUCTION ARE APPARENT THEREIN: ROOTEDNESS (THE SINGLE ROOT) AND RELATIONAL, DYNAMIC ROOTING (RHIZOME). IN ADDITION, THE PRESENCE OF BLACK POETRY IN THE FEMININE IS A SIGNIFICANT FEATURE.

PALAVRAS-CHAVE: LITERATURA NEGRA, LITERATURA AFRO-BRASILEIRA, IDENTIDADE, ENRAIZAMENTO RELACIONAL, POESIA NEGRA NO FEMININO.

KEYWORDS: BLACK LITERATURE, AFRICAN BRAZILIAN LITERATURE, IDENTITY, RELATIONAL ROOTING, BLACK POETRY IN THE FEMININE. 


\section{ntrodução}

Em 1987, defendemos uma tese de doutorado na USP com o titulo de $V$ ozes negras na poesia brasileira: contraponto com a poesia de língua francesa do Caribe. Defendeu-se a tese de que os principais constantes que caracterizam a assim chamada "literatura negra brasileira" eram os seguintes:

a) existência fora da legitimidade conferida pelo campo literário instituído;

b) emergência do eu-enunciador que reivindica sua identidade negra, ou seja, sua pertença a um imaginário afro-brasileiro que urge se reconstruir no Brasil;

c) construção de uma cosmogonia que remonta ao período anterior às travessias transatlânticas nos navios negreiros, isto é, a um restabelecimento de elos culturais com a África;

d) ordenação de uma nova ordem simbólica, fazendo emergir na poesia elementos ligados ao mundo da escravidão como instrumentos de tortura, transformando-os em símbolos de resistência;

e) reversão dos valores e avaliação do outro, na tentativa de tornar positivos elementos que se constituíam, em função da construção de estereótipos, em fatores de exclusão e/ou alienação do negro, como o cabelo pixaim, o formato do nariz etc.

A poesia tenta colocar os "signos em rotação", parafraseando Octavio Paz, fazendo desses signos negativos fatores de orgulho e fundadores da reconstrução identitária (BERND, 1987(b), p. 279-296).

Refletindo hoje, mais de vinte anos após a defesa dessa tese, com vistas à elaboração do presente artigo, pergunto-me sobre as razões de falar em "vozes negras" e não em "escritura negra". Penso que naquela época apenas iniciavam-se na academia brasileira estudos sobre as "literaturas menores", no sentido atribuído a esta expressão por Deleuze e Guattari, ou seja, de literaturas minorizadas no interior do sistema. Era mais prudente naquele contexto falar em "vozes negras na poesia brasileira" do que propriamente em poesia negra. Contudo, a pesquisa revelou um corpus que, embora publicado de maneira marginal, por pequenas editoras ou por conta dos próprios autores, assumia paulatinamente contornos próprios e transitava da vOz à letra, para retomarmos o belo título do livro de Paul Zumthor A letra e a voz. 
(1993). Oriundas de uma cultura de base oral, as comunidades negras no Brasil deixaram marca indelével em nosso cancioneiro e na MPB; a emergência de poemas e contos, cuja publicação vem se tornando contínua desde os anos 1970, é reveladora da migração da voz à letra - o que não representa de modo algum negação do valor da oralidade (voz), mas desejo de (re)construção do identitário também no domínio da escrita (letra).

Do levantamento efetuado na tese, foi possível compor a obra Poesia negra brasileira: antologia, editada em 1992, integrando cem anos de produção literária, ou seja, desde o discurso poético fundador de Luís Gama, em 1859, até o surgimento do grupo Quilombhoje nos anos 1970. A segunda edição dessa antologia, que se encontra no prelo, comprova o vigor que vem adquirindo a poesia negra ou afro-brasileira nos últimos vinte anos, caracterizada sobretudo pelo surgimento de "vozes femininas" que vêm contribuir para o amadurecimento dessa produção literária, trazendo a lume o labor da mulher e os diálogos mãe e filha, que transmitem o legado dos substratos culturais africanos ou dos vestígios memoriais dessas culturas. Em grande parte, graças a essas trocas entre mães e filhas, essa cultura sobreviveu e é sobre tal embasamento que hoje se constrói a identidade negra, fundamento da literatura afro-brasileira.

\section{Poesia negra ou afro-brasileira?}

No Brasil, a partir da década de 1970, iniciou-se um debate sobre como denominar a literatura caracterizada pela emergência de um eu enunciador que se assume como negro, identificando-se com a preservação do patrimônio cultural de origem africana. Foi a partir dessa época que se passou a adotar o termo literatura negra. O século XXI trouxe a consolidação do uso dos termos afro-brasileiro e afrodescendente (do inglês afro-descendent), visto que o termo "negro" poderia indicar a epidermização do conceito, isto é, a definição de uma expressão artística pela cor da pele dos autores. Segundo Sueli Meira Liebig (2003, p. 21), "afro-brasileiro é o termo politicamente correto para designar a pessoa da chamada 'raça negra', nascida em nosso país”.

Revendo os títulos das principais antologias e obras teórico-críticas, publicadas entre 1980 e 2010, a respeito dessa literatura, é possível afirmar que, com o passar do tempo, a expressão literatura negra vem sendo substituída 
pelo termo literatura afro-brasileira, embora ambas as denominações coexistam. Entre diversas obras já publicadas verificamos, a título de exemplificação, a variação de nomenclatura nos títulos: Antologia contemporânea da poesia negra brasileira (1982), Negro e cultura no Brasil (1987), Negritude e literatura na América latina (1987), Introdução à literatura negra (1988), Brasil afro-brasileiro (2001), Poéticas afro-brasileiras (2002), Identidades negras no romance brasileiro contemporâneo (2009), Antologia de Literatura afro-brasileira (site literafro $\left.{ }^{1}, 2004\right)$, Dicionário de personagens afrobrasileiros (2009). Esses títulos confirmam que ainda hoje ambas expressões são tomadas como sinônimos por muitos, cabendo ao autor, seja teórico, poeta ou ficcionista, a escolha da expressão que melhor corresponda a seu posicionamento.

De acordo com estudos realizados por diversos autores teóricos a respeito de sua singularidade, é possível afirmar que a literatura negra ou afro-brasileira apresenta especificidades, entre as quais:

a) a temática dominante é o negro na sociedade, o resgate de sua memória, tradições, religiões, cultura e a denúncia contra o drama da marginalidade do negro na sociedade brasileira devido, sobretudo, à persistência de diferentes formas de preconceito;

b) o ponto de vista é o do negro que emerge no poema como o eu enunciador, assumindo as rédeas de sua enunciação;

c) a linguagem possui vocabulário próprio associado à oralidade da cultura negra;

d) o imaginário corresponde ao conjunto de representações que as comunidades negras constroem sobre si mesmas e mediante as quais se opera a paulatina construção identitária.

Eduardo de Assis Duarte, autor de vasta antologia disponível no site literafro, em artigo intitulado "Por um conceito de literatura afro-brasileira", define a literatura afro-brasileira:

a) pela temática: preferencialmente temas relativos ao negro;

b) pela autoria: "literatura é discursividade e a cor da pele será importante enquanto tradução textual de uma história coletiva e/ou individual” (DUARTE, 2008, p. 15);

1. http://www.letras.ufmg.br/literafro/ 
c) pelo ponto de vista: relato dos fatos a partir de uma ótica negra;

d) pela linguagem: vocabulário, ritmo, sonoridades das línguas africanas;

e) pelo público: literatura destinada preferencialmente a um público negro que busca se conscientizar.

A partir de tal definição, o pesquisador opta pela denominação "afro-brasileira", relacionando a cor da pele enquanto "tradução textual". A pesquisadora Luiza Lobo também opta pela denominação "literatura afro-brasileira", pois, segundo ela, a apelação é necessária para "arrancar a literatura negra do reduto reducionista da literatura em geral que a trata como tema folclórico, exótico ou como estereótipo" (LOBO apud DUARTE, 2008, p. 22). Assim, o conceito de literatura afro-brasileira associa-se à existência, no Brasil, de uma articulação entre textos dada por um modo negro de ver e sentir o mundo, transmitido por um discurso caracterizado, seja no nível da escolha lexical, seja no nível dos símbolos utilizados ou da construção do imaginário, pelo desejo de resgatar uma memória negra esquecida. A assim chamada literatura afro-brasileira ou negra, na preferência de grande número de poetas, é negra porque exprime a experiência comum de opressão e de preconceitos sofridos por um grupo que anseia por exprimir plenamente sua subjetividade. Revogase, assim, uma poética tradicional, que imperava na literatura brasileira, onde o negro era o outro, era objeto (citado na terceira pessoa do discurso, ou seja, "aquele de quem se fala"), para passar a sujeito da enunciação, ou seja, aquele que fala em primeira pessoa do singular ou do plural (quando o poeta se coloca como porta-voz da comunidade à qual pertence).

\section{As tendências identitárias}

Relendo a produção poética afro-brasileira - desde suas origens com Luís Gama em 1859 até os dias atuais -, é possível apontar tendências distintas de construção identitária que não se apresentam em termos diacrônicos, isto é, em uma perspectiva de "evolução" no tempo, mas que por vezes se entrecruzam e convivem no âmbito da poética de um mesmo autor.

A tendência ao enraizamento identitário (raiz única) alicerça-se na afirmação identitária a partir da recuperação de resíduos memoriais que podem unir 
a comunidade negra em sua luta contra preconceitos e até discriminações remanescentes na sociedade brasileira ainda hoje. Esse processo pode tender a construções identitárias redutoras - de raiz única - já que o quadro de referências nos quais se apoiam irá limitar-se ao âmbito da comunidade negra. Se por um lado, em determinados momentos da caminhada rumo à plena afirmação das subjetividades, essas ações afirmativas fazem-se necessárias, há o risco desse tipo de identidade construir-se sem levar em consideração as alteridades da nação brasileira, que se autoproclama mestiça, criando barreiras e cordões de isolamento. Exemplifica essa tendência o poema Justiça vidente de Lepê Corrêa:

As minhas palavras de pedra

Hoje as quero rolando pelas ladeiras

Nas mãos dos moleques de rua,

Rompendo telhados de vidro

Dos antigos maus vizinhos, das caras da cor da lua

Quero as palavras de pedra pelas ruas da cidade (CORRÊEA, 1996, p. 119).

A outra é a tendência ao enraizamento dinâmico e relacional (rizoma), onde a base da argumentação é o conceito criado por Michel Maffesoli de enracinement dinamique que, ao mesmo tempo em que considera fundamental a afirmação da identidade, preconiza sua construção no respeito à diversidade e na abertura para a relação com o outro. Trabalha com a perspectiva de que vários níveis de identidade podem ser contemplados simultaneamente e de que o sujeito negro é também brasileiro, profissional, pertencente a um gênero e desempenha um papel na sociedade que ele quer igualitária e solidária.

Alguns falam de enracinerrance (enraizerrância), ou seja, prefiguram movimentos identitários em constantes processos de mobilidade e de abertura às demais culturas em presença no Brasil e nas Américas. Rita Godet, citando o escritor haitiano Jean-Claude Charles, define enracinerrance como um neologismo que funde os termos enraizar e errância. "Esse termo expressaria a abertura ao outro e ao alhures (ailleurs em francês), mas a partir de si e para voltar a si” (GODET, 2010, p. 194). O historiador canadense, Jocelyn Létourneau afirma que a enracinerrance "é uma passagem libertadora, mas também sofrida em direção ao outro como uma etapa necessária ao ciclo de reprodução do eu 
que comporta uma dimensão crítica sobre si capaz de conduzir à mudança" (apud GODET, 2010, p. 194).

Edimilson de Almeida Pereira, de Juiz de Fora, inaugura prolífica vertente poética que contempla figurações da alteridade, como no poema O grito:

A palavra tem sido o lugar onde levantamos abrigo. Na plantação, no garimpo, tecemos o grito, origem do que falamos. O que foi registro de rebeldia não se aplacou, irrompe na página desnorteando os cães de caça. O grito espreita atrás da escrita, não confia em setas, escolhe os atalhos. Os cães foram ensinados a varar a noite e o tempo. A palavra, no entanto, é um edifício e se alarga para as margens da floresta (PEREIRA, 2003, p. 211).

\section{A poesia afro-brasileira no feminino}

A poética negra no feminino constitui-se, na contemporaneidade, em um ponto forte da literatura afro-brasileira. Segundo Edilene Machado Pereira (2010, p. 3), "por sofrerem dupla discriminação, de raça e de gênero, foram [negados às mulheres negras] direitos sociais básicos como a escolarização. Assim, enquanto as mulheres brancas entraram no mercado de trabalho já escolarizadas, as mulheres negras, mesmo sempre tendo trabalhado, não contaram com o benefício da escolarização". Atualmente, elas vêm conquistando o acesso à educação e ao mercado de trabalho, o que garante uma situação privilegiada de fala. Assumindo as rédeas da própria enunciação, as escritoras coadunam, em seu fazer literário, a busca de afirmação da identidade feminina e negra.

Gostaríamos de iniciar essa fase bem recente da literatura afro-brasileira, em que se nota a predominância do resgate da memória social, do minucioso labor no trato da linguagem e de construções identitárias rizomáticas, analisando as diferentes estratégias do trabalho da memória em três poetas contemporâneas: Miriam Alves, Leda Maria Martins e Conceição Evaristo. Procuraremos avaliar suas táticas de expressão textual, que se situam em um espaço intervalar entre memória e esquecimento, procurando resgatar imaginários de herança afro e atribuir a si próprias e às comunidades às quais estão ligadas uma memória longa. As raízes dessa memória de longa duração serão buscadas na herança africana, trazendo à tona: 
a) uma memória histórica, rememorando fatos da história do negro no Brasil deletados da historiografia oficial devido à condição que os descendentes de africanos ocupavam na sociedade;

b) uma memória familiar, que parte em busca dos ensinamentos e da sabedoria contida na oralitura das gerações que as antecederam.

\title{
Miriam Alves: duas dimensões identitárias
}

O importante na poesia de Miriam Alves é que talvez seja ela das poucas poetas a conseguir conciliar a busca de duas dimensões de sua identidade: a identidade negra é buscada sem anular a dimensão da identidade feminina com a qual a autora também se preocupa. A decifração de si mesma passa pela indagação de seu papel na sociedade ao mesmo tempo como negra e como mulher. O ser oprimido é aqui o negro, sendo a primeira do grupo Quilombhoje - ao qual pertence desde seus primórdios no final dos anos 1970 - a introduzir questões de gênero em sua poética. Assim, sua poesia deixa de enclausurar-se na construção de uma única dimensão identitária, introduzindo outros temas como a valorização da sabedoria que recebeu da ancestralidade pela linha materna, ampliando, assim, o horizonte de recepção de sua obra. No poema Afro-brasileiras, reflete sobre a falta de reconhecimento da resistência feminina durante a escravidão:

\author{
Mães, irmãs, esposas \\ anônimas mulheres guerreiras \\ força move pensamentos passos \\ gerações foram às ruas \\ lutas \\ sustento \\ dignidade \\ sonho melhor \\ avós, mães, tias \\ aves Marias \\ aves marinhas \\ silêncio e anonimato
}




\author{
Presença \\ voz de contínuas esperanças \\ banir pesadelos \\ da vida do país
}

(ALVES, 2008, p. 99)

\title{
Leda Maria Martins: memória e oralitura
}

A poesia de Leda Maria Martins traz consigo o resgate da memória, derivada da oralitura africana expressa através dos rituais religiosos, como os congados mineiros. Com linguagem de grande clareza a autora elege temáticas como racismo, exclusão e desigualdade social, realizando, muitas vezes, um diálogo com o leitor, a fim de demonstrar como o negro é visto na atualidade. Ao contrário de alguns dos autores que abordam o mesmo tema, Leda ao mesmo tempo em que busca o reconhecimento do negro na sociedade, compartilha de suas dores, apontando caminhos possíveis para uma poética da relação, visando a harmonia entre brancos e negros. Por estar em contato direto com outras manifestações artísticas, como o teatro, a dança e a música, a autora inscreve em seus poemas elementos rítmicos e sonoros, dando uma dimensão de universalidade à sua obra. Lamenta, por exemplo, o desconhecimento do povo brasileiro da herança africana:

Eu não estive lá quando queimaram os mortos

e dançaram nas bordas do fogo.

Nem quando se abraçaram ébrios das vitórias

e nas miragens por vir

lavraram novos totens

e os celebram.

(MARTINS, 1999, p. 52)

No poema Linhagem, sublinha a importância capital para a poética afrobrasileira de nutrir-se do manancial da cultura africana, voltando-se para a rememoração da linhagem à qual quer vincular-se, apontando para a urgência de alimentar-se "dos ritmos ancestrais": 
Coma, infante

do teu pranto

dos vasos alheios

de todas as ceias

postas.

Coma dos ritmos

ancestrais

das estancas

e arabescos

dos murais

$[\ldots]$

Tome da escrita

o almíscar da vOz,

da letra

o apetite do verbo,

do tempo,

o repouso do instante.

De todas as ceias postas

coma

para que teu enjôo

não seja seco.

(MARTINS, 1999, p. 39)

\section{Conceição Evaristo: álbuns de família}

Conceição Evaristo demonstra, na obra Poemas da recordação e outros movimentos (2008), o orgulho de ser mulher e de ser negra e traz à tona a memória identitária do negro, representada por lembranças de infância das histórias contadas por sua família, valorizando assim a oralidade. Em sua poesia aborda questões ligadas à maternidade e aos dramas da mulher negra, desde as gerações que vieram da África na condição de escravos até os dias de hoje, 
como no poema Vozes-mulheres. A poeta também apresenta a resistência, a angústia, o medo e o receio da mulher escrava ao fugir do dono para não ter de se distanciar do filho recém-nascido e ressalta a importância do conhecimento, da sabedoria e da experiência de seus ancestrais, além de relacionar o sofrimento da senzala com a dura realidade da comunidade negra de hoje, lutando contra a discriminação e a pobreza.

A voz de minha bisavó ecoou

criança

nos porões do navio.

Ecoou lamentos

De uma infância perdida.

A voz de minha avó

ecoou obediência

aos brancos-donos de tudo.

A voz de minha mãe

ecoou baixinho revolta

No fundo das cozinhas alheias

debaixo das trouxas

roupagens sujas dos brancos

pelo caminho empoeirado

rumo à favela.

A minha voz ainda

ecoa versos perplexos

com rimas de sangue

e

fome.

(EVARISTO, 2008, p. 10)

\section{Considerações finais}

Considero capitais os esforços dessas autoras em reconstituir cosmogonias a partir de vestígios. Nesse sentido, cito a historiadora da cultura Sandra Pesavento em sua reflexão sobre as marcas culturais (trace): 
A história cultural tem se empenhado, entre outras coisas, a resgatar estas tais sensibilidades do passado, ou as práticas culturais do sensível, através das marcas que deixaram nos materiais de arquivo, nas artes, na literatura. Estes seriam, por assim dizer, os indícios ou pegadas deixados pelo homem e que se oferecem à leitura, desde que iluminados por uma pergunta ou questão. Em todas elas - até mesmo nos documentos oficiais de que falava Huisinga - é possível encontrar registros da alma, traços do mundo sensível de uma outra época; (PESAVENTO, 2007, p. 15)

Dessa forma, a produção poética afro-brasileira contemporânea em geral e, de modo particular, a poesia no feminino, reconstrói, a partir de marcas, indícios e pegadas, uma geografia do sensível negro-brasileiro, reconstruindo panoramas culturais que a História pretendeu apagar. Essa poesia afro-brasileira renovada propõe a ordenação de uma nova ordem simbólica e a reversão dos valores que outrora exilavam o negro para então integrá-lo a uma proposta de sociedade multiétnica e pluricultural da qual poderá emergir, enfim, o Brasil como uma verdadeira democracia racial.

\section{Referências bibliográficas}

ALVES, Miriam. Afro-brasileiras. In QUILOMBHOJE (Org.). Cadernos negros 31. São Paulo: Quilombhoje, 2008. p. 99.

BERND, Zilá. Negritude e literatura na América Latina. Porto Alegre: Mercado Aberto, 1987.

Vozes negras na poesia brasileira: contraponto com a poesia de língua francesa do Caribe. 1987(b). 375 p. Tese (Doutorado em Letras) - Universidade de São Paulo, São Paulo, 1987. Mimeografia.

- Introdução à literatura negra. São Paulo: Brasiliense, 1988.

(Org.). Poesia negra brasileira: antologia. Porto Alegre: AGE/IEL, 1992.

COLINA, Paulo (Org.). Axé: antologia contemporânea da poesia negra brasileira. São Paulo: Global, 1982.

CORREAA, Severino Lepê. Justiça vidente. In QUILOMBHOJE (Org.). Cadernos negros 19. São Paulo: Quilombhoje; Anita, 1996. p. 119.

DALCASTAGNE, Regina. Identidades negras no romance brasileiro. In: WALTY, Ivete; CURY, Maria Zilda F.; ALMEIDA, Sandra Regina G. (Org.). Mobilidades culturais: agentes e processos. Belo Horizonte: Veredas \& Cenários, 2009. p. 99-123. 
DUARTE, Eduardo de Assis. Por um conceito de literatura afro-brasileira. Terceira margem, Rio de Janeiro, n. 23, p. 113-138, jul./dez. 2010.

EVARISTO, Conceição. Vozes-mulheres. In Poemas da recordação e outros movimentos. Belo Horizonte: Nandyala, 2008. p. 10.

FIGUEIREDO, Maria do Carmo Lanna; FONSECA, Maria Nazareth Soares. Poéticas afro-brasileiras. Belo Horizonte: Mazza; PUC-MG, 2002.

FONSECA, Maria Nazaret Soares (Org.). Brasil afro-brasileiro. 2. ed. Belo Horizonte: Autêntica, 2001.

GODET, Rita Olivieri. Errância/migração/migrância. In: BERND, Zilá (Org.). Dicionário das mobilidades culturais: percursos americanos. Porto Alegre: Literalis, 2010. p. $189-210$.

LIEBIG, Sueli Meira. Dossiê black \& branco: literatura, racismo e opressão nos Estados Unidos e no Brasil. João Pessoa: Ideia, 2003.

LOPES, Helena Theodoro; SIQUEIRA, José Jorge; NASCIMENTO, Maria Beatriz. Negro e cultura no Brasil. Rio de Janeiro: UNIBRADE : UNESCO, 1987.

MAFFESOLI, Michel. Sobre o nomadismo: vagabundagens pós-modernas. Rio de Janeiro: Reccord, 2001.

MARTINS, Leda Maria. Os dias anônimos. Rio de Janeiro: Sette Letras, 1999.

PEREIRA, Edilene Machado. Marias que venceram na vida: uma análise da ascensão da mulher negra via escolarização em Salvador, BA. África e africanidades, Rio de Janeiro, v. 2, n. 8, fev. 2010.

PEREIRA, Edimilson de Almeida. O grito. In Casa da palavra: obra poética 3. Belo Horizonte: Mazza, 2003. p. 211.

PESAVENTO, Sandra Jatahy. Sensibilidade: escrita e leitura da alma. In LANGUE, Frédérique (Org.). Sensibilidades na história: memórias singulares e identidades urbanas. Porto Alegre: Ed. da Universidade - UFRGS, 2007. p. 9-21.

SOUZA, Licia Soares de. (Org.). Dicionário de personagens afrobrasileiros. Salvador: Quarteto, 2009.

ZUMTHOR, Paul. A letra e a voz: São Paulo: Companhia das Letras, 1993.

Recebido em 16 de agosto e aprovado em 20 de setembro de 2010. 